\title{
Assessment of knowledge, attitude, and practice toward acne vulgaris among the Lebanese young adult population
}

\author{
Samer Sakr', Diana Hachem², Ali Ghaddar ${ }^{3}$, Nedal Taha ${ }^{1}$
}

${ }^{1}$ Department of Biological and Chemical Sciences, School of Arts and Sciences, Lebanese International University, Beirut, Lebanon, ${ }^{2}$ School of Pharmacy, Lebanese International University, Beirut, Lebanon, ${ }^{3}$ Department of Biomedical Sciences, School of Arts and Sciences, Lebanese International University, Beirut, Lebanon

Corresponding author: Dr. Samer Sakr, E-mail: samer.sakr@liu.edu.lb

\begin{abstract}
Background: Acne vulgaris, a chronic skin condition, is the one of the common diseases to impact the quality of life. The importance of quality of life has led many toward self-therapy. Since self-medication is a normal practice among the Lebanese population, this study was undertaken to evaluate the knowledge, assessment, and practice of acne patients, as well as to assess the awareness about a widely used medication for severe acne: Isotretinoin. Material and methods: This cross sectional study included young adult subjects of the Lebanese community. A questionnaire was self-administered to 502 participants. Results: Acne was prevalent in $61.55 \%$.of the subjects. Self-medication was reported in $50.20 \%$ of subjects. The most common reasons for self-medication were identifying as mild illness (18.92\%) and therapy from previous prescriptions (14.94\%). The majority of the treatment was topical creams. When asked about the knowledge of the drug isotretinoin, their source of information was doctors (27.69\%), yet 24.90\% referred to family and friends. $34.06 \%$ were not aware of the side effects and contraindications of this drug. Conclusion: The Lebanese community lacks the sufficient knowledge about self-medication risks. A wide collaboration and many efforts between the health care systems should provide proper awareness to patients.
\end{abstract}

Key words: Acnes; Self-treatment; Knowledge; Awareness; Isotretinoin; Roaccutane

\section{INTRODUCTION}

Acne vulgaris is one of the most common skin diseases of the pilosebaceous gland, associated with a chronic non inflammatory lesions or inflammatory lesions. It is clinically characterized by comedones, papules, pustules, nodules and in some cases, scarring [1]. Acne vulgaris is a common dermatological condition typically presenting at adolescent. However, the condition is also prevalent and persistent into adulthood, with $64 \%$ of the 20 to 29 years old and $34 \%$ of the 30 to 39 years old male and female populations experiencing acne [2]. It encompasses a multifactorial disease process that can affect individuals regardless of age, sex, or nationality. Acne is a disease which leads to low self-esteem, social embarrassment, social withdrawal, and depression [3]. The treatment of acne is challenging and often chronic. In order to use a therapy that works quickly to clear up acne, affordable and convenient, many have adapted a behavior of self-medication.

Self-medication means obtaining and consuming one or more drugs without the advice of a physician either for diagnosis, prescription, or surveillance of the treatment [4]. Patients usually have the habit of using drugs prescribed to other family members or friends for the same type of illness to avoid physician consultation. Self-medication thus forms an integral part of self-care, which can be defined as the primary public health resource in the health care system [5]. A previous study in Lebanon has reported self-medication as a frequent problem in Beirut area [6].

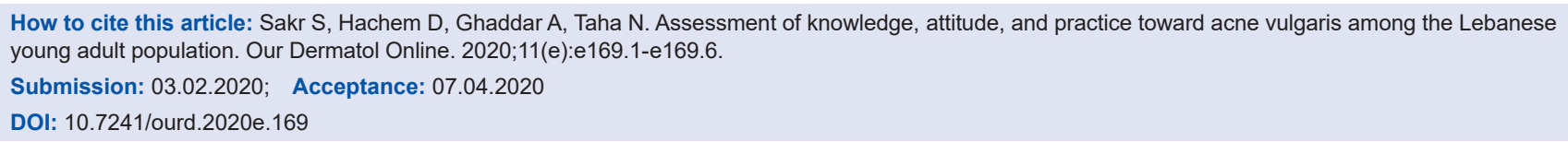


According to the WHO, rational self-medication helps in the prevention and treatment of minor pathological conditions at an affordable cost. However, it is associated with undesirable drawbacks, for example, serious adverse effects, drug interactions, polypharmacy, emergence of resistant pathogens, and also wastage of resources. Many studies have revealed that adults are more vulnerable to the practice of self-medication due to their low perception of risk associated with the use of drugs, knowledge of drugs, easy access to internet wider media coverage on related health issues, ready access to drugs, level of education, and social status [7]. Among acne drugs in the Lebanese market, Isotretinoin, better known as the brand Roaccutane, is the most famous and used medication, not only for a severe condition but to establish a better looking skin, even with very mild and rare cases of non-inflammatory lesions.

Oral isotretinoin (13-cis-retinoic acid), a vitamin A derivative, was first approved as treatment for severe acne by the US Food and Drug Administration (FDA) in 1982. It reduces the amount of oily substance (i.e. sebum) made by glands in the skin, inhibits sebaceous gland activity, growth of habitant bacteria (Cutibacterium acnes formally known as Propionibacterium acne), inflammation, and improve hyper keratinization (shedding) of skin. Oral isotretinoin is also useful for the management of less severe acne that is treatment-resistant or that is producing either physical or psychological scarring [8]. However, it is associated with a variety of side effects the most notable of these is teratogenicity when used during pregnancy [9]. But, ophthalmic and musculoskeletal effects and effects on plasma lipids and liver function tests are also acknowledged side effects [10]. For the past 40 years, oral isotretinoin has been considered the treatment of choice against acnes vulgaris despite its adverse effects. However, recently and based on clinical trials it has been reported that oral antibiotics or topical treatments are more efficient in treating the inflammatory lesions caused by acnes [11].

During our literature search, we could not find any study regarding knowledge, attitude, and practice (KAP) of self-medication for acne in the Lebanese population. Hence, this study was carried out to evaluate the (KAP) of self-medication for acne among the Lebanese population. We further extrapolated our study to include the Knowledge, attitude, and awareness of the drug isotretinoin and its adverse effect.

\section{MATERIAL AND METHODS}

This is a cross-sectional community based descriptive survey among the young adult Lebanese population. The study has been performed during the period from January 2018 to June 2018. A self-administered hard copy questionnaire was randomly administered to a sample of 530 subjects. Participants were approached mainly in a university. Data collectors, pharmacy students, were specially trained for this research. 502 subjects agreed to fill the questionnaire, corresponding to a response rate of around $95 \%$, as approximately $5 \%$ did not accept to take part of this questionnaire. The questionnaire took around 10 minutes to fill. The questionnaire was a 28 item inventory titled Standard KAP, the items were generated from the literature $[12,13]$ and adaptation from previous studies and a two-step validation process was followed for its accuracy and uniqueness. The questionnaire was divided into two parts. The first part addressed the general knowledge (4 questions), attitudes (4 questions), and practices ( 3 questions) related to acne in general. Examples of questions included: Do you think acne is a bacterial infection? a-Yes, b-No; I read leaflet instructions: a-Yes, b-No; Treatment: a-I treat my own acnes, b- I follow what a doctor or healthcare professional suggests, c-Both.

The second part included questions to assess the perception of self-medication for acne and the knowledge, attitude, and awareness of patients regarding isotretinoin. Examples of questions included: I know the drug Roaccutane (isotretinoin) used to treat acnes: a- Yes, b-No; I am aware of the side effects and contraindications of Roaccutane: a-Yes, b-No; I check my liver function tests every month during the course of the treatment: a-Yes, b-No.

Statistical analysis of the data was performed using SPSS. The voluntary nature of participation and assurance of data confidentiality was mentioned explicitly and informed consent was obtained.

\section{RESULTS}

\section{Characteristics of the Sample and Acnes Statistics}

In this study, in which 502 respondent have participated, only a different number of subjects have answered to the diverse questions in the survey as referred in the data tables. 
The study sample included 502 individuals in which $68.33 \%(n=343)$ were females and $31.07 \%(n=156)$ were males. The mean age of participants was between $19-20$ years old $32.89 \%$ and $20-29$ years old $56.17 \%$.

The prevalence of acne in the sample was $61.55 \%$ $(n=309)$. In Table 1, the statistical analysis among those who had acnes, shows that acne appeared in the summer season mostly to $44.98 \%(n=139) .57 .93 \%$ $(n=179)$ of the participants who had acne declared acnes history in the family. An overwhelming majority of the respondents with acne $74.76 \%(n=231)$ had an oily skin. We investigated acne distribution and the degree of acnes to assess the severity from mild to severe. $73.14 \%(n=226)$ of the participants with acne reported that acnes covered part of the face.

Knowledge about acnes was analyzed using score yes/ no. Table 2 shows participants' knowledge and beliefs about acne. Among the participants in the survey, $63.94 \%(n=321)$ of the respondents knew that acne is caused by bacteria. On the other hand, $82.07 \%$ $(n=412)$ knew that popping acnes can lead to scarring. The major source of information regarding acnes was reported to be friends and family members $30.48 \%$ $(n=153)$ followed by pharmacists $26.10 \%(n=131)$. According to the results for the 502 subjects, the main contributors to the occurrence of acnes are hormones

Table 1: Diagnosis of acne among participants

\begin{tabular}{|c|c|c|}
\hline & Yes & No \\
\hline & n (\%) & n (\%) \\
\hline suffering from acne $(n=500)$ & $309(61.55 \%)$ & $191(38.05 \%)$ \\
\hline season acnes appeared $(n=294)$ & n (\%) & \\
\hline Autumn & $25(8.10 \%)$ & \\
\hline Spring & $40(12.94 \%)$ & \\
\hline Winter & $41(13.27 \%)$ & \\
\hline Summer & $139(44.98 \%)$ & \\
\hline More than one season & $49(15.86 \%)$ & \\
\hline \multirow[t]{2}{*}{ Cases in the family $(n=309)$} & $n(\%)$ & n (\%) \\
\hline & $179(57.93 \%)$ & $130(42.07 \%)$ \\
\hline Frequency of acne $(n=309)$ & $\mathrm{n}(\%)$ & \\
\hline Rarely & $59(19.09 \%)$ & \\
\hline Sometimes & $124(40.13 \%)$ & \\
\hline Often & $65(21.04 \%)$ & \\
\hline Always & $61(19.74 \%)$ & \\
\hline Skin type $(n=309)$ & $\mathrm{n}(\%)$ & \\
\hline Oily & $231(74.76 \%)$ & \\
\hline Dry & $62(20.06 \%)$ & \\
\hline More than one option & $16(5.18 \%)$ & \\
\hline Severity of acne $(n=309)$ & $\mathrm{n}(\%)$ & \\
\hline Part of the face & $226(73.14 \%)$ & \\
\hline Whole face & $42(13.59 \%)$ & \\
\hline Chest & $17(5.50 \%)$ & \\
\hline More than one option & $24(7.77 \%)$ & \\
\hline
\end{tabular}

$80.28 \%(n=403)$ followed by skin type $71.51 \%(n=359)$ and chocolate consumption $64.74 \%(n=325)$.

As shown in Table 2, $50.20 \%(\mathrm{n}=252)$ of the participants reported self-treatment of acne. The most common

Table 2: Knowledge and practices of participants toward the causes and factors contributing to Acnes and their treatments

\begin{tabular}{|c|c|c|}
\hline & Yes & No \\
\hline & n (\%) & n (\%) \\
\hline \multicolumn{3}{|c|}{$\begin{array}{c}\text { Knowledge of participants toward causes and factors } \\
\text { contributing to Acne }\end{array}$} \\
\hline \multicolumn{3}{|c|}{ Sources of information } \\
\hline Textbook $(n=453)$ & $76(15.14)$ & $377(75.10)$ \\
\hline Drug advertisement/internet/media $(n=452)$ & $69(13.74)$ & $383(76.29)$ \\
\hline Pharmacist $(n=448)$ & $131(26.10)$ & $317(63.15)$ \\
\hline Prescriptions issued to others $(n=449)$ & $42(8.37)$ & $407(81.08)$ \\
\hline Self-decision $(n=449)$ & $77(15.34)$ & $372(74.10)$ \\
\hline Friends/Family members $(n=449)$ & $153(30.48)$ & 296(58.96) \\
\hline Internet $(n=449)$ & $101(20.12)$ & $348(69.32)$ \\
\hline Acne caused by bacterial infection ( $n=495$ ) & $321(63.94)$ & 174(34.66) \\
\hline Popping pimples causes scaring $(n=493)$ & 412(82.07) & $81(16.13)$ \\
\hline Factors contributing to acne & $\mathrm{n}(\%)$ & $n(\%)$ \\
\hline Chocolate is a factor $(n=502)$ & $325(64.74)$ & $177(35.26)$ \\
\hline Skin type is a factor $(n=502)$ & $359(71.51)$ & $143(28.49)$ \\
\hline Hormones are factors $(n=502)$ & $403(80.28)$ & 99(19.72) \\
\hline
\end{tabular}

\begin{tabular}{lll}
\hline \multicolumn{3}{c}{$\begin{array}{c}\text { Self-practices of participants for the treatment of acnes in } \\
\text { human subjects }\end{array}$} \\
\hline $\begin{array}{lll}\text { Treat own acne }(\mathrm{n}=464) & 252(50.20) & 212(42.23) \\
\text { Follow a doctor/health care professional } & 321(63.94) & 161(32.07)\end{array}$
\end{tabular}

\section{$(\mathrm{n}=482)$}

\begin{tabular}{|c|c|c|}
\hline Reason for self-therapy & $\mathrm{n}(\%)$ & n (\%) \\
\hline Mild illness $(n=369)$ & 95(18.92) & $274(54.58)$ \\
\hline Can't afford doctor's fees $(n=349)$ & $23(4.58)$ & $326(64.94)$ \\
\hline Therapy from previous prescription $(n=346$ ) & $75(14.94)$ & $271(53.98)$ \\
\hline No time to go to the doctor $(n=269)$ & $39(7.77)$ & $230(45.82)$ \\
\hline $\begin{array}{l}\text { Embarrassed to discuss own symptoms } \\
(\mathrm{n}=249)\end{array}$ & $7(1.39)$ & $242(48.21)$ \\
\hline $\begin{array}{l}\text { Pharmacological knowledge of acne drugs } \\
(n=349)\end{array}$ & $44(8.76)$ & $305(60.76)$ \\
\hline Easy access to drugs in pharmacy $(n=349)$ & $38(7.57)$ & $311(61.95)$ \\
\hline $\begin{array}{l}\text { Treatment application and duration } \\
(\mathrm{n}=259)\end{array}$ & n (\%) & \\
\hline Complaint disappears & $97(19.32)$ & \\
\hline Drug finishes & $27(5.38)$ & \\
\hline Indication of previous prescriptions & 18(3.59) & \\
\hline When required & 104(20.72) & \\
\hline More than option & 13(2.59) & \\
\hline \multirow[t]{2}{*}{$\begin{array}{l}\text { Read the label/leaflet instructions } \\
(n=231)\end{array}$} & n (\%) & n (\%) \\
\hline & $114(22.71)$ & $117(23.31)$ \\
\hline $\begin{array}{l}\text { Reason for not reading label/leaflet } \\
\text { instructions }\end{array}$ & $\mathrm{n}(\%)$ & $\mathrm{n}(\%)$ \\
\hline No need to read $(n=117)$ & $45(38.46)$ & $72(61.54)$ \\
\hline No time $(n=117)$ & $17(14.53)$ & $100(85.47)$ \\
\hline Difficult to understand $(n=117)$ & $35(29.91)$ & $82(70.08)$ \\
\hline Read the expiry date of the drug $(n=392)$ & $332(66.13)$ & $60(11.95)$ \\
\hline Drugs used for therapy & $\mathrm{n}(\%)$ & $\mathrm{n}(\%)$ \\
\hline Topical cream $(n=422)$ & $233(46.41)$ & 189(37.65) \\
\hline Oral $(n=422)$ & $108(21.51)$ & $314(62.55)$ \\
\hline Cleaning lotions $(n=421)$ & $211(42.03)$ & $210(41.83)$ \\
\hline
\end{tabular}


reasons for self-medication in present study were identified by illness as being mild $18.92 \%(n=95)$ followed by the use of prescribed therapy from previous prescriptions $14.94 \%(n=75)$ and the pharmacological knowledge of acne drugs $8.76 \%(n=44) .20 .72 \%$ $(\mathrm{n}=104)$ respondents stop the treatment when required, or when complaint disappears $19.32 \%(n=97)$. $23.31 \%(n=117)$ admitted that they do not read the drug leaflet. The major reason behind not reading the leaflet is the assumption that they have enough knowledge and there is no need to read the leaflet in $38.46 \%(n=45)$ and/or it is difficult to understand in $29.91 \%(n=35)$. On the other hand, $66.13 \%(n=332)$ of the respondents indicated that they read the expiry of the drug. The choice of therapy used for treatment was cleaning solutions for $42.03 \%(n=211)$, topical creams $46.41 \%(n=233)$ and oral drugs $21.51 \%(n=108)$.

Furthermore, we extrapolated our survey to assess the knowledge of participants about isotretinoin. As presented in Table 3, out of the subjects who answered the questions, $59.76 \%(\mathrm{n}=300)$ claimed to have knowledge about isotretinoin. The main source of information was doctors $27.69 \%(n=139)$ followed by family members $24.90 \%(n=125)$ and then pharmacists $9.16 \%(n=46)$. The majority of those who completed the question $59.36 \%(\mathrm{n}=298)$ did not know the mechanism of action of the drug. $34.06 \%(n=171)$ were not aware of the side effects and contraindications of the drug.

In regards to the course duration, and as summarized in Table 3, 69 of the respondents continued using isotretinoin for a period between 2 to 4 months. 102 out of the 126 who responded to the question considered the treatment as successful. 46 of acne patients were complaining from reappearance of acne and the majority stated during the summer. 101 of patients suffered from dry skin, 58 of which had mood changes, 41 had low energy, 34 complain of dry eye and the few encountered other side effects. 78 out of 147 did not perform a liver test every month during the treatment with isotretinoin.

\section{DISCUSSION}

Several studies have evaluated opinions and perceptions about acnes in various areas of the world. Gaining a better understanding of how individuals perceive acnes is significant for treatment and awareness strategies.
Table 3: Assessment of participant's knowledge about the uses, duration, concern and side effects of the drug Isotretinoin

\begin{tabular}{|c|c|c|}
\hline & Yes & No \\
\hline & n (\%) & n (\%) \\
\hline \multicolumn{3}{|c|}{ Population knowledge assessment of the drug isotetinoin } \\
\hline Isotretinoin used to treat acne $(n=469)$ & $300(59.76)$ & 169(33.67) \\
\hline $\begin{array}{l}\text { Source of information about the } \\
\text { drug }\end{array}$ & n (\%) & n (\%) \\
\hline Doctors $(n=391)$ & 139(27.69) & $252(50.20)$ \\
\hline Internet $(n=384)$ & $38(7.57)$ & $346(68.92)$ \\
\hline Family $(n=384)$ & $125(24.90)$ & $259(51.59)$ \\
\hline Pharmacist $(n=379)$ & $46(9.16)$ & $333(66.34)$ \\
\hline Newspaper $(n=374)$ & 13(2.59) & $361(71.91)$ \\
\hline $\begin{array}{l}\text { Knowledge about mechanism of action } \\
(n=360)\end{array}$ & $62(12.35)$ & 298(59.36) \\
\hline $\begin{array}{l}\text { Aware of side effect and contraindications } \\
(n=355)\end{array}$ & $184(36.65)$ & $171(34.06)$ \\
\hline $\begin{array}{l}\text { Two months for acne disappearance } \\
(\mathrm{n}=223)\end{array}$ & $63(12.55)$ & $160(31.87)$ \\
\hline Isotretinoin suitable for everyone $(n=317)$ & $33(6.57)$ & $284(56.57)$ \\
\hline
\end{tabular}

\begin{tabular}{|c|c|c|}
\hline $\begin{array}{l}\text { Time period for Isotretinoin } \\
\text { administration }(n=150)\end{array}$ & $\mathrm{n}(\%)$ & \\
\hline$>2$ months & $32(6.37)$ & \\
\hline 2 months & $13(2.59)$ & \\
\hline 3 months & 17(3.39) & \\
\hline 4 months & $7(1.39)$ & \\
\hline$<4$ months & $81(16.13)$ & \\
\hline \multirow[t]{2}{*}{ Successful treatment $(n=126)$} & $n(\%)$ & n (\%) \\
\hline & 102(20.32) & $24(4.78)$ \\
\hline $\begin{array}{l}\text { Time period for therapy success } \\
(n=73)\end{array}$ & $n(\%)$ & \\
\hline 1 month & $18(3.59)$ & \\
\hline 2 months & $11(2.19)$ & \\
\hline 3 months & $15(2.99)$ & \\
\hline 4 months & 10(1.99) & \\
\hline 6 months & 10(1.99) & \\
\hline 7 months & $2(0.40)$ & \\
\hline 12 months & $4(0.80)$ & \\
\hline 24 months & $1(0.20)$ & \\
\hline 36 months & $1(0.20)$ & \\
\hline 60 months & $1(0.20)$ & \\
\hline \multirow[t]{2}{*}{ Reappearance of acne $(n=76)$} & $\mathrm{n}(\%)$ & n (\%) \\
\hline & $46(9.16)$ & $30(5.98)$ \\
\hline Season of reappearance $(n=28)$ & $\mathrm{n}(\%)$ & \\
\hline Autumn & $0(0.00)$ & \\
\hline Spring & $7(1.39)$ & \\
\hline Winter & $6(1.19)$ & \\
\hline Summer & $13(2.59)$ & \\
\hline More than option & $2(0.40)$ & \\
\hline Side effect during the therapy & $\mathrm{n}(\%)$ & $\mathrm{n}(\%)$ \\
\hline Vision problems $(n=286)$ & $16(3.19)$ & $270(53.78)$ \\
\hline Dry skin $(n=287)$ & $101(20.12)$ & $186(37.05)$ \\
\hline Joint pain $(n=287)$ & $15(2.99)$ & $272(54.18)$ \\
\hline Liver problems $(\mathrm{n}=285)$ & $12(2.39)$ & $273(54.38)$ \\
\hline Increased triglycerides $(n=287)$ & $11(2.19)$ & $276(54.98)$ \\
\hline Dry eye $(n=287)$ & $34(6.77)$ & $253(50.40)$ \\
\hline Nose bleeding ( $n=286)$ & $14(2.79)$ & $272(54.18)$ \\
\hline
\end{tabular}


A worldwide study of patients with acnes reported that $50 \%$ of the individuals knew little or nothing about acnes [14]. The present study assessed 502 Lebanese subjects of biological and non-biological background on how they interpret acne. Although the insufficiency of the data from previous studies was a limitation, the present survey provides a better understanding to the prevalence of self-medication.

The prevalence of acnes in our study was found $61.55 \%$. A previous study conducted by Khattar et al, 2010 in Lebanon has reported acnes vulgaris as the most common skin disease [15]. In our study, $63.94 \%$ of the respondents correlated the acnes with bacteria, $82.07 \%$ knew that popping pimples causes scaring. $64.74 \%$ of the subjects believed there is a relation between acne and chocolate consumption. Although the relation between chocolate and acnes was considered a myth, several recent studies have linked the consumption of dark chocolate to acne exacerbation $[16,17]$. In addition, their knowledge about skin type (71.51\%) and hormones $(80.28 \%$ ) as contributor factors to acne.

Knowing that $48.80 \%$ of our subjects are of biology major, $48.41 \%$ are non-biology, and the prevalence of knowledge to acne is of higher than expected among both discipline, this may indicates one the factors that led to self-medication. In previous studies, various reasons have been reported for engaging selfmedication. These include previous experience, mild diseases, availability of medications, affordability and saving time $[18,19]$. When comparing these studies with present statistics, we found out answers to why they practice self-therapy were diverse, either acne is a mild illness (18.92\%), or $14.94 \%(n=75)$ use previous therapy (14.94\%), as well as others mentioned but less common reasons. These reasons depend on the environment and populations.

Many healthcare organizations have made important statements on self-care and self-medication. According to WHO: "it has become widely accepted that selfmedication has in important place in the health care system. Improvements in people's general knowledge, level of education and socio-economic status in many countries form a reasonable basis for successful selfmedication." [20]. The international council of nurses (ICN): "self-medications a key component of self-care that is particularly significant in an era of increasing chronic illness and well informed health care consumers. Optimizing responsible self-medication is an important and underused resource for health and provides an opportunity for collaboration and consultation among consumers, nurses, pharmacists and physicians" [21].

Through the conduct of the study, we evaluated the general knowledge and the responsibility among patients to have an idea about how far the education of the individual has reached in regards to their own health. Data showed, 104 patients use the treatment whenever it is required or felt needed, and 94 stop it when complaint disappears. (23.31\%) out of 231 do not read the leaflet. While oral isotretinoin was known widely to be used for acne, (59.36\%) of 360 participants lacked the knowledge about its mechanism of action, (34.06\%) about the side effect and the right therapy needed.

Even though the knowledge and diagnosis of acne was of high prevalence, our result indicates that the necessary awareness about the consequences of self-medication is far from being a completely safe practice. Further studies should illustrate on other potential risk of self-medication practices, like incorrect self-diagnosis, incorrect choice of therapy, dangerous drug interactions.

\section{CONCLUSION}

When self-medication is used safely, medications contribute to better health and to a longer and greater quality of life. However, a vast number of patients are not well aware and informed about the associated risks, contraindication, and adverse effects. Self-medication is an alarming issue. Proper health education should be given to patients. While pharmacists play a valuable role promoting safe, appropriate, effective use of all medications, all health care systems/professionals should improve communication skills and increase awareness. Enough information should be provided about each condition, its treatment, use of medicine, general advice, and adverse side effects.

\section{ACKNOWLEDGMENTS}

We thank Gabrielle Bou Habib, Mohammad Badran, Stephany Maalouf, Tala Kaddoura, Yervand Kondrahjian and Zeinab Noor Mnawar, for their technical assistance while conducting the survey.

\section{Statement of Human and Animal Rights}

All procedures followed were in accordance with the ethical standards of the responsible committee on human experimentation (institutional and national) and with the Helsinki Declaration of 1975, as revised in 2008 . 


\section{Statement of Informed Consent}

Informed consent was obtained from all patients for being included in the study.

\section{REFERENCES}

1. Akdogan N, Dogan S, Atakan N, Yalçin B. Association of serum hormone levels with acne vulgaris: Low estradiol level can be a pathogenetic factor in female acne. Our Dermatol Online. 2018;9:249-56.

2. Bhate $\mathrm{K}$, Williams HC. Epidemiology of acne vulgaris. $\mathrm{Br} \mathrm{J}$ Dermatol. 2013;168:474-85.

3. Kręgiel M, Żuchowska A, Tomaszewska K, Wojciechowska A, Jędrowiak A, Tabara K, et al. Acne fulminans in the course of oral isotretinoin treatment. Presentation of cases. Our Dermatol Online. 2017;8:210-4.

4. Montastruc JL, Bondon-Guitton E, Abadie D, Lacroix I, Berreni A, Pugnet $G$, et al. Pharmacovigilance, risks and adverse effects of self-medication. Therapie. 2016;71:257-62.

5. Warth J, Puth MT, Tillmann J, Beckmann N, Porz J, Zier U, et al. Cost-related medication nonadherence among over-indebted individuals enrolled in statutory health insurance in Germany: a cross-sectional population study. BMC Health Serv Res. 2019;19:887.

6. Cheaito L, Azizi S, Saleh N, Salameh P. Assessment of self-medication in population buying antibiotics in pharmacies: a pilot study from Beirut and its suburbs. Int J Public Health. 2014;59:319-27.

7. Simone ED, Tartaglini D, Fiorini S, Petriglieri S, Plocco C, Muzio MD. Medication errors in intensive care units: nurses' training needs. Emerg Nurse. 2016;24:24-9.

8. Landis MN. Optimizing isotretinoin treatment of acne: Update on current recommendations for monitoring, dosing, safety, adverse effects, compliance, and outcomes. Am J Clin Dermatol. 2020;21:411-9.

9. Ahmad HM. Analysis of clinical efficacy, side effects, and laboratory changes among patients with acne vulgaris receiving single versus twice daily dose of oral isotretinoin. Dermatol Ther. 2015;28:151-7.

10. Brzezinski P, Borowska K, Chiriac A, Smigielski J. Adverse effects of isotretinoin: A large, retrospective review. Dermatol Ther. 2017;30:10.1111/dth.12483.

11. Costa CS, Bagatin E, Martimbianco ALC, da Silva EM, Lúcio MM, Magin P, et al. Oral isotretinoin for acne. Cochrane Database Syst Rev. 2018;11:CD009435.

12. Al-Harbi M. Concerns and awareness of acne patients about isotretinoin in qassim region of saudi arabia. Int J Health Scien. 2010;4:47-51.

13. Karamata VV, Gandhi AM, Patel PP, Desai MK. Self-medication for acne among undergraduate medical students. Indian J Dermatol. 2017;62:178-83.

14. Dréno B, Thiboutot D, Gollnick H, Finlay AY, Layton A, Leyden JJ, et al. Large-scale worldwide observational study of adherence with acne therapy. Int J Dermatol. 2010;49:448-56.

15. Khattar JA., Hamadeh GN, Rahi AC, Musharrafieh UM. Common dermatologic diseases among students at a tertiary care center in Lebanon. Lebanese Med J. 2010;58:195-8.

16. Vongraviopap S, Asawanonda P. Dark chocolate exacerbates acne. Int J Dermatol. 2016;55:587-91.

17. Chalyk N, Klochkov V, Sommereux L, Bandaletova T, Kyle N, Petyaev I. Continuous dark chocolate consumption affects human facial skin surface by stimulating corneocyte desquamation and promoting bacterial colonization. J Clin Aesth Dermatol. 2018;11:37-41.

18. Auta A, Shalkur D, Omale S, Abiodun AH. Medicine knowledge and self-medication practice among students. African J Pharmaceut Res Develop. 2012;4:6-11.

19. Goel DD. Self-medication patterns among nursing students in North India. IOSR J Dental Med Scien. 2013;11:14-7.

20. Guidelines for the regulatory assessment of medicinal products for use in Self-medication, WHO 2000. Available: http:/ / apps.who.int/ medicinedocs/pdf/s2218e/s2218e.pdf. Accessed: 2019 March 11

21. Bennadi D. Self-medication: A current challenge. J Basic Clin Pharm. 2013;5:19-23.

Copyright by Samer Sakr, et al. This is an open-access article distributed under the terms of the Creative Commons Attribution License, which permits unrestricted use, distribution, and reproduction in any medium, provided the original author and source are credited.

Source of Support: Nil, Conflict of Interest: None declared. 